\title{
A Development of Islamic E-Commerce Ethics Model
}

\author{
NOR HAPIZA MOHD ARIFFIN 1
}

\begin{abstract}
The purpose of this paper is to study the Islamic ethical elements in online e-Commerce (EC) transactions and develop an ethical business model. Based on a preliminary investigation, it was found that sellers who use EC were not aware and did not have proper guideline to guide them on the Islamic business ethics during online transactions. This paper aims to propose an Islamic EC Ethics model to increase the awareness among businesses in EC transactions. Both qualitative and quantitative methods were deployed as the primary method where experts were interviewed, and questionnaire were distributed. Using selective sampling method, data collection from 100 respondents who have performed online selling transactions were collected. Statistical Package for Social Science (SPSS) was used to analyze the data collected and followed by model development. Finally, it was validated by an expert. The proposed Islamic EC ethics model provides proper guideline for online sellers while performing online transactions by guide them about the right and wrong things to do in accordance to Islamic beliefs.
\end{abstract}

Keywords: E-commerce, Islamic Ethics, Business Model, Online transaction

Revolution of technology makes things simpler and faster. Online transaction is one of the evolutions that has been overgrowing nowadays. By performing an online transaction on an ECommerce (EC) platform, both seller and buyer are obligated to fulfill necessary conditions expected. Both are bound by the transactional contract created where the seller is expected to honor the duty to provide the expected goods in good conditions and the buyer to provide expected means of payment for the goods purchased. In executing the transactional conditions, usually some form of ethical behavioral were observed by both parties. Seller and buyer should know the ethics and rules of the processes during the transaction. Regardless of platforms, either online or offline, business ethics exists where sellers and buyers are expected to give respects to each other.

Several Muslim people were still unfamiliar with the conditions of their transactions, in particular, to be in alignment with the Islamic perspective and customer rights (Jusop et al, 2017). A practiced Muslim complies to the Islamic standard and requirement in all aspect of life including businesses. There are different rules to guide different practices. In Islamic business transaction, a shariah compliance transaction follows muamalat, a jurisprudence of commercial law in Islam. Same goes to EC transactions, the Islamic practices should also be followed in order to fulfil the requirement and the rules as for Muslims.

EC means the electronic purchases and sales of products and services through the Internet, network and other digital technology, for instance, mobile device, laptop and personal computer with the use of computerized business transactions. The word EC has many meanings in the research of EC. It relies on the view of experts, academics, business and professionals to match their research. Based on literature definition of EC, this study defines EC as a mean to allow selling and buying activities that are executed by both seller and buyer to initiate, conduct, and service the transaction occurred between them on the Internet. The initiate stage is where seller

\footnotetext{
${ }^{1}$ Nor Hapiza Mohd Ariffin, Ph. D. Senior lecturer at Faculty of Computer and Mathematical Sciences, Universiti Teknologi Mara, Shah Alam, 40450, Selangor, MALAYSIA. Email: hapiza@uitm.edu.my
} 
creates its business existence in the Internet before transaction begin, and the buyer is looking for potential items for purchase through surfing and searching the Internet. Then, the conduct of the selling and buying happen where both buyer and seller interact to fulfill the transaction through the online medium. The transaction finishes when both seller and buyer follows-up with each other for post-sales services, if any, using social or online medium. That completes one cycle of an EC transaction. Since EC is conducted virtually through the devices and Internet, there must be specific conditions and rules that should be understood to make sure the legality and trustworthy of e-commerce, in this study's context, in Islam (Zainul et al, 2004).

The EC ethics in transactions include all parts of business processes (Aziz et al, 2011). For example, in marketing, it should be a clear and concise in the communication of the products offered by the seller. The information about the product should be defined clearly and with no intention of misleading or fraud (Hashim et al, 2007). For instance, the photos of the product displayed is expected to be at par with the real product, including being promoted on the EC platform. The online photo has to be displayed clearly on the screen of the devices including the detailed information and specification, the prices and the type of delivery and payment itself. In order to achieve this arrangement, the buyer must then receive the actual message about the product. Finally, in terms of communication, whether offline (using letter or flyers) or online, buyer and seller must be transparent.

EC has a similar definition to traditional trade. Similar practices and laws are created to equally treat both traditional and EC trades. However, in Islam, some practices in traditional trade do not comply with its' beliefs, for example the general prohibition of alcohol, gambling, usury, and uncertainty. Therefore, certain conditions must be met and allowed to be modified to comply with specific laws and conditions from an Islamic point of view (Zainul et al., 2004). From the Islamic perspective, a web-based business has a comparative definition with the customary trade. However, a few guidelines and commitments must be lined up with the need of Islamic standards and admissible by Islam (ibid).

In business transactions, there is no exception to the exercise of customers' right. Customers' rights mean that the customers have the right to safety, to be informed, to choose, and to be heard (NHM Ariffin, 2012). In Islam, rights conveyed numerous definitions. Traditional Islamic legal scholar Ibn Nujaiym characterised rights as 'the qualification of an individual to a thing and a selective task', which is the essential element of the general idea of rights for the rights conveyor (Zainul et al., 2004). Therefore, what Islam is practicing in upholding individual's rights, in essence, is truly what customers right is all about. Muslim community supports the idea of trade via EC. This assistance should be used as much as possible, because Islam promotes the growth of EC in conformity with Islamic law (Yusron et al, 2019).

Philosophical ethics is an informal framework in which social punishments, including rejection and ostracism, are concentrated. A number of different and well-established ethical theories exist in philosophical ethics (Velasquez, 2012). Deontological (duty-based actions), utilitarian (subsequent acts), contract or rights-based acts (deeds based on character) are the theories most common (Sharma \& Lijuan, 2014). Honesty, truthfulness and genuineness are the essential moral estimation of Islam. A business person (seller) must be straightforward, honest and transparent in the entirety of his business dealings. There is no extent of conning, talking lies, swearing excessively and false publicising in the Islamic system of business (Zainul et al., 2004). While exertion put to induce individuals to purchase their items, publicists are inclined to abuse uncertainty, disguise actualities, misrepresent and utilise mental way to deal with influence buyers to purchase as per their passionate needs, not to reasons. These traps are particularly successful and put the buyers in progressively helpless position under the EC condition, as buyers just depend on Web data to settle on buying choice. Along these lines, certainty of buyers assumed a significant job in the progression of any business concern. As regards EC, aspects such as business ethics, payment systems, contracts, buying and selling systems and consumer and manufacturer rights must be taken into consideration (Research and Markets, 2020). Once completed, it can be stated that the use of EC is permitted based on the Islamic purchasing and 
selling law because this can lead to profit while remaining consistent with Islamic purchasing and selling values (Yusron et al., 2019).

The gaining in the worldwide Muslim customers' expenses on this area is because the growing stronger and bigger of halal e-commerce industry (Jusop et al., 2017). In addition to Muslim nations and customers, the halal sector has increased. Halal industry potential results from the growth of the population of Muslims which is estimated to rise to 2.2 billion by 2030, of 1.7 billion individuals in 2014 (ibid). The Malaysian government has taken numerous measures to turn the nation into a significant worldwide centre for halal, recognizing the significance of the sector.

Based on the preliminary interview with expert who is a lecturer from Academy of Contemporary Islamic Studies (ACIS), UiTM Shah Alam, the expert in area Islamic ethics confess that some sellers who use EC as their business platform still do not have a proper guideline about the Islamic ethics while doing the online transaction. The sellers (business owner) especially the Muslim community should be able to understand the basic knowledge of the Islamic ethics in every e-commerce transaction focus on the seller side activity in the business itself. Besides, sellers in EC are not aware the importance of Islamic ethics in EC and how ethical values play a major role in their business transactions, especially among Muslims. Some seller who using EC as their online transaction platform may take for granted the practice of Islamic ethics. Cheating, fraud, corruption and other elements which are not in conformity with the rules and regulations of Islamic business transactions are forbidden to be transacted in the market (Muhammad et al, 2017), however may not well be observed by the online sellers. Businesses, in the Muslim world, are confronted with some ethical issues and sometimes do not know how to deal or cope with the ethical issues at work.

There are three objectives to be achieved, which are to identify the online transactional elements in Islamic and conventional businesses transactions, to analyze the factors of Islamic ecommerce ethics in e-commerce transactions and to propose an ethical Islamic business model to increase the awareness among businesses in e-commerce transaction.

\section{Method}

The scope of this study is within the interest of the Islamic ethics in EC transaction and has involved getting experts perspectives on the Islamic and Syariah EC transactions in order to know more about the Islamic ethics in business transaction and the elements that influence the ethics. Other than experts, a survey was performed to collect data from respondents, who are the sellers who run the business online. Responses from practicing sellers are important for reliable and critical analysis with the purpose of developing a good reference of Islamic EC Ethical Business model. This study focuses on the Business-to-Consumer (B2C) type of business which includes the small businesses that sell goods or services directly to consumers.

The first stage of this research, knowledge acquisition, allows researchers to conduct a literature review based on the previous study (Creswell \& Creswell, 2018). Review on existing literature on concept of EC and its activities led to identification of transaction process in EC and ethical issues arise in the activities. Focusing more on the subject, the EC concept is refined to fit into Islamic concept of muamalat. Next, research on components of the EC ethics led to identification of a suitable EC ethics model by Sharma \& Lijuan (2014) that can fit the elements of ethics with the definition of individual's Islamic rights. This model was used as a conceptual model to develop the Islamic EC ethics model that can guide EC transaction among or with Muslims. 


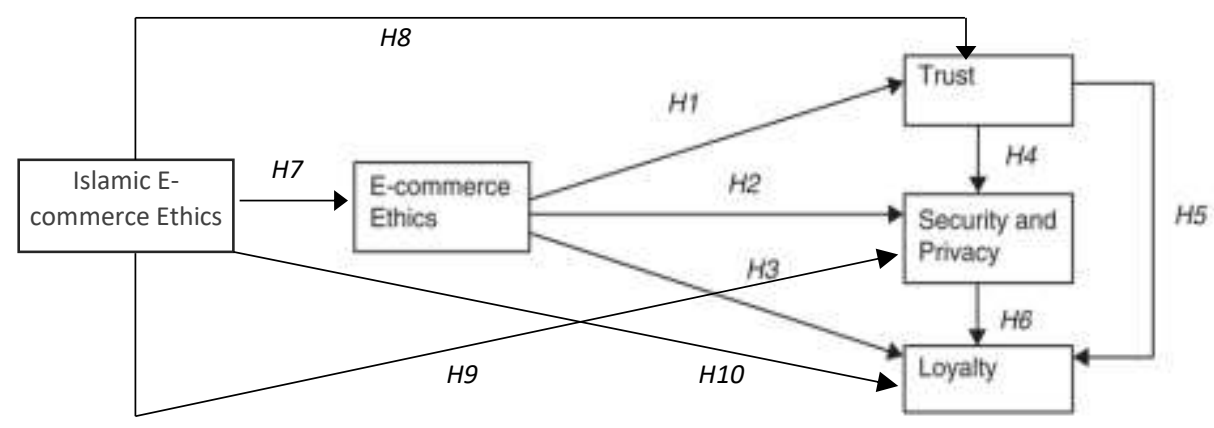

Fig. 1: Conceptual model of Islamic and Conventional EC ethics (Adapted from Sharma \& Lijuan, 2014)

Once a conceptual model is available, the research moved to data collection, the second stage of research. The data collection can be separated into two categories which are primary data and secondary data. The primary data, which were collected using a survey, was conducted based on 10 hypotheses, defined through the conceptual model.

H1: There is a significant relationship between conventional e-commerce ethics and trust.

H2: There is a significant relationship between conventional e-commerce ethics and security and privacy.

H3: There is a significant relationship between conventional e-commerce ethics and loyalty.

H4: There is a significant relationship between trust and security and privacy.

H5: There is a significant relationship between trust and loyalty.

H6: There is a significant relationship between security and privacy and loyalty.

H7: There is a significant relationship between Islamic e-commerce ethics and conventional e-commerce ethics.

H8: There is a significant relationship between Islamic e-commerce ethics and trust.

H9: There is a significant relationship between Islamic e-commerce ethics and security and privacy.

H10: There is a significant relationship between Islamic e-commerce ethics and loyalty.

The survey was conducted through social medium and real-life meeting. For the purpose of content validity, an interview with an expert who have knowledge in Islamic ethics in ecommerce transaction was conducted to validate the questionnaire and the elements of mualamat in Islamic ethics in e-commerce transactions. This study used convenience sampling as it is the most widely used method because it is highly speedy, easy to use, cost-effective, and also easily accessible to the sample respondents (Azizan et. al. 2017). This study used the online and offline methods of data collection. For the online method, Google Form was used and for offline, a hardcopy of questionnaires was used. Lastly, the questionnaires were distributed to the actual respondents.

The next phase of this study was data analysis. During this phase, the researcher had to access the business model components of Islamic ethics in e-commerce transaction from the data and information collected in the previous phase which was the data collection phase. All the data collected were analyzed through quantitative analysis technique by using Statistical Package for Social Sciences (SPSS) tool using descriptive and inferential test (Landau et al, 2003). The purpose of this activity was to determine the element of the Islamic ethics e-commerce transaction. The 
fourth phase was a model development which used the result of the data used to develop a business model based on the Islamic ethics and e-commerce transaction.

\section{Results and Discussion}

Data were collected using a questionnaire designed into 2 sections which are Section $\mathrm{A}$ and Section B. Section A is about demographic information of the respondents and Section B is about the elements of E-Commerce Ethical Islamic Business Model Transaction. For the purpose of this study, there are two dependent variables which are Conventional E-commerce ethics and Islamic E-Commerce Ethics and three independent variables which are Security and Privacy, Trust and Loyalty.

The questionnaires were designed based on a five-point Likert scale. The five-point Likert scale ranges from (1) to (5) representing strongly agree and strongly disagree respectively, (2) and (4) represent moderately agree and disagree while (3) represent neutral. A total of 120 questionnaires were administered and 20 were returned, therefore the response rate is 83 percent. SPSS software was the statistical tools used to capture and analyze the data from the questionnaire.

\section{Overview of Section A}

Below are the findings for section A which is about demographics profile of the respondents.

TABLE 1 : Respondent Demographics

\begin{tabular}{|c|c|c|}
\hline \multicolumn{2}{|l|}{ Character } & \multirow{2}{*}{\begin{tabular}{|l|} 
Percent (\%) \\
\end{tabular}} \\
\hline Gender & Male & \\
\hline & Female & 69 \\
\hline \multirow[t]{4}{*}{ Age } & $20-30$ years & 87 \\
\hline & $31-40$ years & 7 \\
\hline & $41-50$ years & 6 \\
\hline & Above 50 years & 0 \\
\hline \multirow[t]{12}{*}{ Type of Business } & Selling products & 72 \\
\hline & Provide services & 22 \\
\hline & Manufacturing & 7 \\
\hline & Retailer & 4 \\
\hline & Supplier & 3 \\
\hline & Wholesaler & 1 \\
\hline & Construction & 1 \\
\hline & Dropship & 1 \\
\hline & Buyer & 1 \\
\hline & Massage & 1 \\
\hline & Takaful & 1 \\
\hline & Food \& Services & 1 \\
\hline \multirow{7}{*}{$\begin{array}{l}\text { Platform Used for } \\
\text { online transactions }\end{array}$} & Social Media & 93 \\
\hline & Website & 32 \\
\hline & $\begin{array}{l}\text { E-marketplace (Shopee, } \\
\text { Lazada, Alibaba etc) }\end{array}$ & 20 \\
\hline & Blog & 5 \\
\hline & Offline & 3 \\
\hline & Online & 2 \\
\hline & Email marketing & 1 \\
\hline
\end{tabular}




\section{Overview of Section B}

There are several findings for Section B which seeks to determine the elements of E-Commerce Ethical Islamic Business Model Transaction. Below are the findings for Section B. Table 2 illustrates about descriptive statistics for the E-commerce ethics constructs. There are 3 independent variables values derived from 100 respondents as seen in Table 2. Based on table 2, it can be seen that Security and Privacy has the highest mean value of 3.83, followed by Loyalty with mean value of 3.82 whereas Trust has the lowest mean value of 3.79 . There is only slightly differences within the means for those elements analyzed. Therefore, it shows that all elements have the same concerns of the respondents for E-commerce ethics.

Descriptive Statistics
\begin{tabular}{|l|l|l|l|}
\hline & N & Mean & Std. Deviation \\
\hline Security and Privacy & 100 & 3.83 & .61858 \\
Loyalty & 100 & 3.82 & .68265 \\
Trust & 100 & 3.79 & .56896 \\
Valid N (listwise) & 100 & & \\
\hline
\end{tabular}

Spearman Rho's correlation coefficient is the test statistics that measure the statistical relationship, or association, between two continuous variables. It is a measure of the strength of the association between the two variables. Therefore, in this research, it was used for hypotheses testing. Table 3 below illustrates the relationship between hypotheses and its value.

TABLE 3 : Hypotheses Result

\begin{tabular}{|l|l|c|l|}
\hline Item & \multicolumn{1}{|c|}{ Hypothesis } & Value & \multicolumn{1}{|c|}{ Results } \\
\hline H1 & $\begin{array}{l}\text { There is a significant relationship between } \\
\text { conventional e-commerce ethics and trust. }\end{array}$ & 0.46 & Accepted \\
\hline H2 & $\begin{array}{l}\text { There is a significant relationship between } \\
\text { conventional e-commerce ethics and security and } \\
\text { privacy. }\end{array}$ & 0.69 & Accepted \\
\hline H3 & $\begin{array}{l}\text { There is a significant relationship between } \\
\text { conventional e-commerce ethics and loyalty. }\end{array}$ & 0.23 & Accepted \\
\hline H4 & $\begin{array}{l}\text { There is a significant relationship between trust } \\
\text { and security and privacy. }\end{array}$ & 0.60 & Accepted \\
\hline H5 & $\begin{array}{l}\text { There is a significant relationship between trust } \\
\text { and loyalty. }\end{array}$ & 0.45 & Accepted \\
\hline H6 & $\begin{array}{l}\text { There is a significant relationship between } \\
\text { security and privacy and loyalty. }\end{array}$ & 0.40 & Accepted \\
\hline H7 & $\begin{array}{l}\text { There is a significant relationship between } \\
\text { Islamic e-commerce ethics and conventional e- } \\
\text { commerce ethics. }\end{array}$ & 0.53 & Accepted \\
\hline H8 & $\begin{array}{l}\text { There is a significant relationship between } \\
\text { Islamic e-commerce ethics and trust. }\end{array}$ & 0.55 & Accepted \\
\hline H9 & $\begin{array}{l}\text { There is a significant relationship between } \\
\text { Islamic e-commerce ethics and security and } \\
\text { privacy. }\end{array}$ & 0.64 & Accepted \\
\hline H10 & $\begin{array}{l}\text { There is a significant relationship between } \\
\text { Islamic e-commerce ethics and loyalty. }\end{array}$ & 0.52 & Accepted \\
\hline
\end{tabular}

Hence, the findings show that all hyphotheses were are accepted. There were are five elements of the business model which is the conventional e-commerce ethics, Islamic ecommerce ethics followed by trust, security and privacy and loyalty. There is a significant relationship between each of the elements of the business model. Both conventional and Islamic 
e-commerce ethics depends on the trust, security and privacy and loyalty. Therefore, Figure 2 below illustrates the Islamic Ethics E-commerce Business Model.

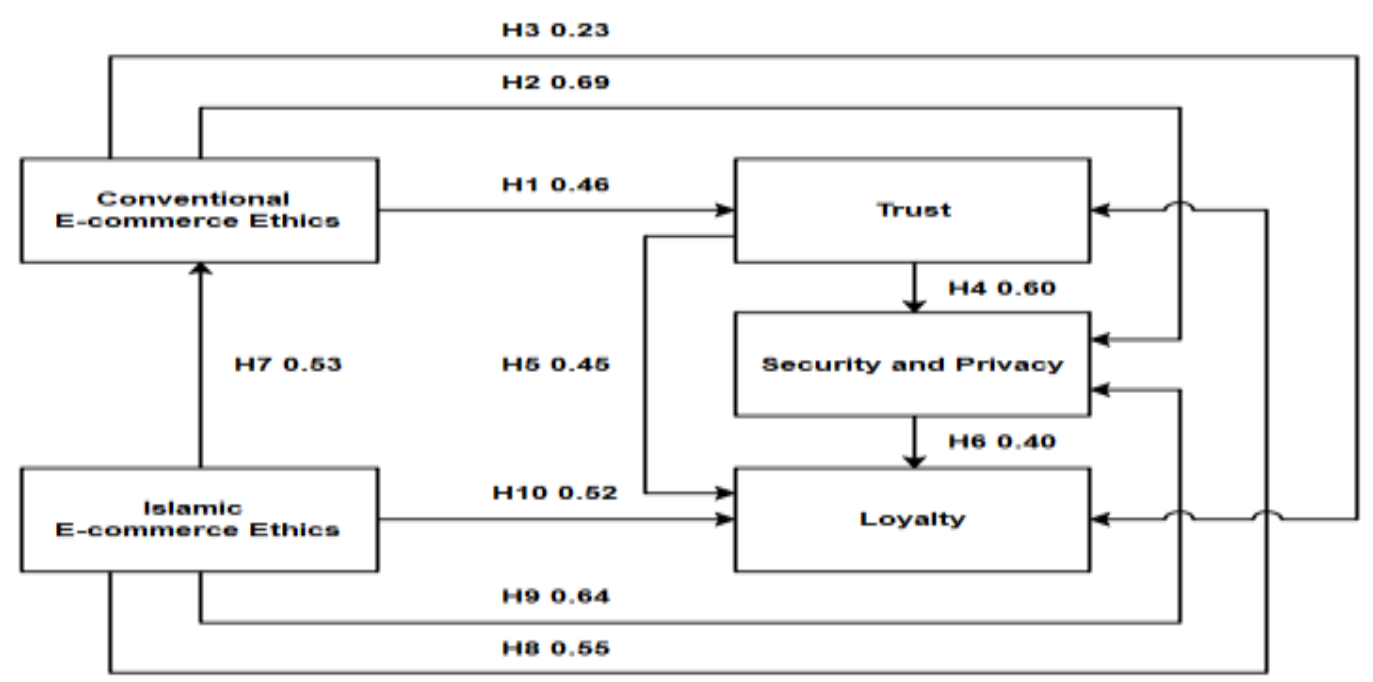

Fig. 2 : Islamic Ethics E-commerce Business Model

Finally, the researcher validated the business template using the documentation evaluation and prototype as the final product. The final product, which was the graphics and content brochure was were validated by experts and users to ensure they understand the business model and both of them agreed with the information in the brochure. Below is Figure 3 that illustrates the end product as a brochure for the society to understand about Islamic ethics E-commerce.

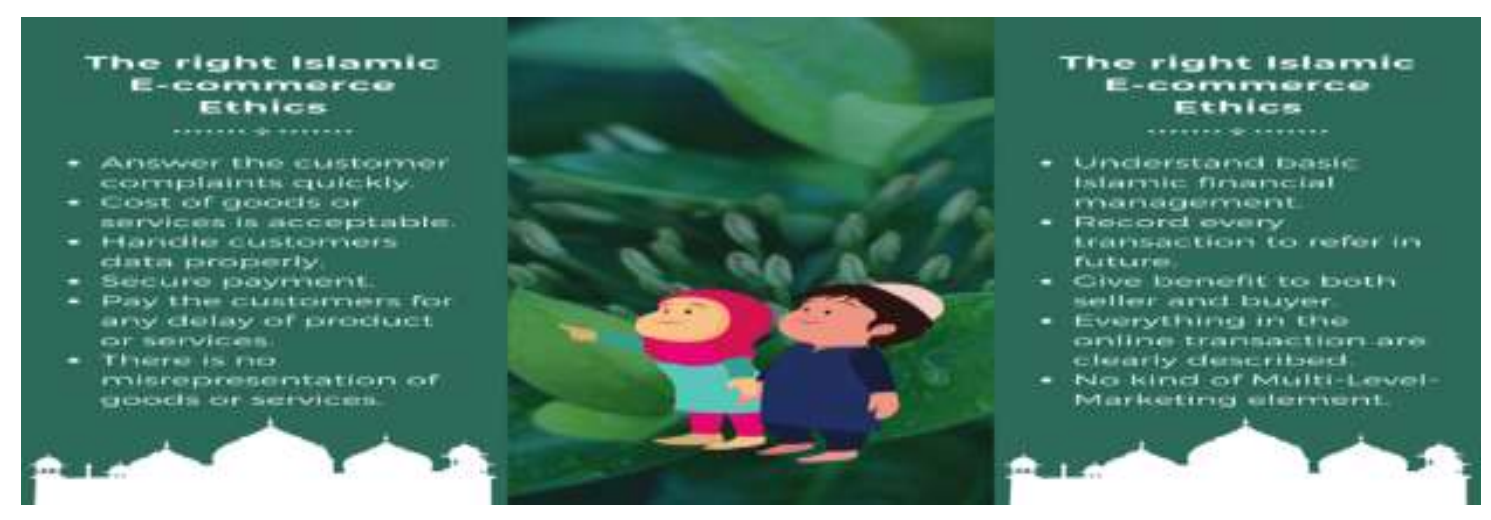

Fig. 3 : Brochure Guidelines of Islamic Ethics E-Commerce

Overall, this study focuses on the beneficial of business owner (seller) and the Muslim community. By providing a guideline of the Islamic ethical business model, it can increase the trustworthy of customers to the business and gain customer satisfaction, loyalty and highlight the transparency of the business. Hence, it provides a platform to practice the Islam guidelines in the business. This study revealed that both either conventional or Islamic e-commerce ethics depends on the trust, security and privacy and loyalty. 


\section{References}

Aziz, A.A., Lokman, A.M. \& Yusof, Z.M. 2011. Information technology ethics: the conceptual model of constructs, actions and control measure. International Journal on Computer Science and Engineering. 3(6): 2580-2588

Azizan, N. H., Mahmud, Z., \& Rambli, A. 2018. Measurement instrument and indicators of subjective well-being: a review paper. Journal of ASIAN Behavioural Studies. 3(11): 22-33. https://doi.org/10.21834/jabs.v3i11.322

Creswell, J. W. \& Creswell, D. J. 2018. Research Design: Qualitative, Quantitative, and Mixed Methods Approaches. (5th ed.). Thousand Oaks: SAGE Publications, Inc.

Hashim, N. A., Hashim, M. \& Abdul Majid, R. 2007. An evaluation of business-to-business electronic commerce marketplaces (e-marketplaces) in Malaysia. Social and Management Research Journal. 4(2): 101-121. https://doi.org/10.24191/smrj.v4i2.5138

Jusop, M., Abdullah, O. Y., Ismail, R. M., Ismail, \& N. A., Yeop, O. 2017. Halal e-commerce measure of success: a consideration of sharia compliance business practice. World Journal of $\begin{array}{llll}\text { Islamic History } & \text { 7ivilization. }\end{array}$ https://doi.org/10.5829/idosi.wjihc.2017.79.87

Landau, S. \& Everitt, B. S. 200). A Handbook of Statistical Analyses Using SPSS. London: Chapman and Hall/CRC.

Muhammad, Muhd Rosydi \& Muhammad, Marjan \& Khalil, Khalil. 2013. Towards shari'ah compliant e-commerce transactions: a review of Amazon.com. Middle-East Journal of Scientific Research. 15 (9): 1229-1236. 10.5829/idosi.mejsr.2013.15.9.11176.

N. H. M. Ariffin, A. R. Hamdan, K. Omar \& N. Janom. 2012. Customer Relationship Management (CRM) implementation: A soft issue in knowledge management scenario. IEEE Colloquium on Humanities, Science and Engineering (CHUSER), pp. 485-489, https://doi: 10.1109/CHUSER.2012.6504363.

Research and Markets. 2020. COVID-19 Impact on e-Commerce \& Online Payments, Worldwide, 2020 - Online Shopper Penetration Increases During the Pandemic. GlobeNewswire. https://www.globenewswire.com/news-release/2020/05/29/2040716/0/en/COVID19-Impact-on-e-Commerce-Online-Payments-Worldwide-2020-Online-ShopperPenetration-Increases-During-the-Pandemic.html: Retrieved: 20 July 2020.

Sharma, G. \& Lijuan, W. 2015. The effects of online service quality of e-commerce websites on user satisfaction. The Electronic Library. 33(3): 468-485. https://doi.org/10.1108/el-102013-0193

Velasquez, M. G. 2011. Business Ethics: Concepts and Cases. (7th ed.). n.l. Pearson.

Yusron Sholikhin, M. \& Nurul Fitri Amijaya, R. 2019. E-Commerce based on the law of buying and selling in Islam. KnE Social Sciences. 3(13): 1360-1370. https://doi.org/10.18502/kss.v3i13.4290

Zainul, N., Osman, F., \& Mazlan, S. H. 2004. E-Commerce from an Islamic perspective. Electronic Commerce Research and Applications. 3(3): 280-293. https://doi.org/10.1016/j.elerap.2004.01.002 